\title{
Development of a Weather-Based Advisory Program for Scheduling Fungicide Applications for Control of White Rust of Spinach
}

\author{
M. J. Sullivan and J. P. Damicone, Department of Entomology and Plant Pathology, and M. E. Payton, Depart- \\ ment of Statistics, Oklahoma State University, Stillwater 74078
}

\begin{abstract}
Sullivan, M. J., Damicone, J. P., and Payton, M. E. 2003. Development of a weather-based advisory program for scheduling fungicide applications for control of white rust of spinach. Plant Dis. 87:923-928.

Weather-based advisory programs were developed and evaluated for timing of fungicide applications to control white rust of spinach (Spinacia oleracea) in three field trials using a susceptible cultivar. The advisory programs were based on previous studies that defined periods of temperature (T) and wetness (relative humidity $\geq 90 \%$, W) that favored disease development. The protectant fungicides mancozeb or maneb (ethylene bisdithiocarbamates; EBDCs) and the systemic fungicide azoxystrobin were applied after 3, 6, 12, 24, and 36 cumulative hours of wetness weighted by temperature $(\mathrm{T} * \mathrm{~W}) . \mathrm{T}^{*} \mathrm{~W}$ programs were compared with an advisory program based on $12 \mathrm{~h}$ of continuous wetness (12-h W), a 7-day calendar program, and a nonsprayed control treatment. Except for the $3-\mathrm{h} \mathrm{T} * \mathrm{~W}$ program, the number of fungicide applications per trial was reduced for all advisory programs compared with the 7-day program. Averaged over the three trials, applications were reduced from 2.7 per trial for the $6-\mathrm{h} \mathrm{T} * \mathrm{~W}$ program to 3.7 per trial for the $36-\mathrm{h} \mathrm{T} * \mathrm{~W}$ and the $12-\mathrm{h} \mathrm{W}$ programs. For the EBDC fungicides, all advisory programs except the 36-h T*W and 12-h W programs reduced incidence and severity of white rust compared with the nonsprayed control. Disease incidence and severity for the 3-h and 6-h T*W programs did not differ from the 7-day program. Compared with the EBDC fungicides, azoxystrobin resulted in reduced disease incidence for each of the spray programs and reduced disease severity for all spray programs except the 7-day program. For azoxystrobin, all advisory programs reduced disease incidence and severity compared with the nonsprayed control. Incidence and severity of white rust did not differ from the 7-day program for the 3-h, 6-h, and 12-h $\mathrm{T}^{*} \mathrm{~W}$ programs. Based on reductions in the number of fungicide applications and the level of disease control, the 6-h and $12-\mathrm{h} \mathrm{T} * \mathrm{~W}$ programs were most efficient advisory programs for the EBDC fungicides and azoxystrobin, respectively.
\end{abstract}

Additional keywords: Albugo occidentalis

Spinach (Spinacia oleracea L.) is a coolseason vegetable crop grown for the processing market on about 1,224 to 2,040 ha each year in Oklahoma. The crop is produced primarily in the Arkansas River Valley during fall, overwinter, and spring production seasons. For spring and fall production, the crop is seeded and harvested during the same season. In overwinter production, the spinach is seeded in the late fall, and plants are allowed to stand over the winter and are harvested in late winter or spring as dictated by temperature. The crop is machine-harvested in bulk with nonselective cutters. White rust, caused by Albugo occidentalis Wilson, is an impor-

Corresponding author: J. P. Damicone E-mail: jpd3898@okstate.edu

Current address of M. J. Sullivan: Department of Plant Pathology, Campus Box 7616, North Carolina State University, Raleigh 27695-7616.

Accepted for publication 18 March 2003.

Publication no. D-2003-0602-01R

(C) 2003 The American Phytopathological Society tant foliar disease of spinach in Oklahoma, Texas, Arkansas, and other areas of spinach production in the eastern United States (3). Symptoms of white rust begin as chlorotic spots on the upper leaf surface $(12,13)$. As lesions develop, small, white, blister-like pustules (sori) are produced on the underside of the infected leaves, rendering them unmarketable $(3,12,13)$. Yield losses of 30 to $100 \%$ have been reported due to a reduction in the quality and marketability of fresh and processing spinach $(1,5)$.

Integrated disease management practices, such as crop rotation, the planting of cultivars with partial resistance, and the application of fungicides, have been used in the management of white rust of spinach (3). The planting of partially resistant cultivars can result in acceptable levels of white rust control without application of fungicides when disease pressure is low (4). However, partially resistant cultivars can become severely infected when environmental conditions are favorable for white rust $(3,4)$. In addition, resistance to white rust is lacking in long-standing cultivars, which are slow to bolt and suitable for the overwinter and spring production seasons. As a result, fungicide application is an important tool in management of white rust.

Growers relied on the use of preventive spray programs with the ethylene bisdithiocarbamate (EBDC) fungicides maneb and zineb for disease control until their registration for use on spinach in the United States was revoked in 1991 $(2,5,6,11)$. From 1991 to 2000, copperbased fungicides, metalaxyl (or mefenoxam), and fosetyl-Al were registered for use on spinach in the United States. Phytotoxicity problems with copper-based fungicides and fosetyl-AL, label restrictions that limit the efficacy of metalaxyl, and the high cost of metalaxyl have limited use of these fungicides by growers.

Azoxystrobin is a recently developed fungicide that has systemic activity against several Ascomycete, Basidiomycete, and Oomycete pathogens on various crops (21). In efficacy studies on spinach in New Jersey (10) and Oklahoma (6,7), azoxystrobin applications made on 7-day intervals provided excellent control of white rust. Control of white rust with azoxystrobin was similar to or significantly better than that with other fungicides tested, but without phytotoxicity problems. In 1999 and 2000, azoxystrobin was available for use on spinach in Oklahoma under an emergency exemption. The fungicide was registered for use on spinach in the United States in 2001.

Environmental conditions affect both the ontogeny of $A$. occidentalis and development of white rust. Sporangia typically germinate indirectly by releasing zoospores, and occasionally directly via a germ tube $(3,12,13)$. Temperature and free moisture were reported to influence the degree of indirect germination under controlled conditions $(12,13)$. Sporangia germinate indirectly at temperatures from 2 to $25^{\circ} \mathrm{C}$, with the highest level of germination occurring from 12 to $16^{\circ} \mathrm{C}$. The presence of free surface moisture is required for indirect germination $(12,13)$. The effects of temperature and wetness period, the duration of relative humidity $(\mathrm{RH}) \geq 95 \%$, on development of white rust have been defined under controlled conditions (19). Plants of a susceptible cultivar were exposed to temperatures from 6 to $28^{\circ} \mathrm{C}$ and intermittent periods of wetness that totaled 3 to $84 \mathrm{~h}$ following inoculation with sporangia. The optimum range of temperature for disease development was from 12 to 
$18^{\circ} \mathrm{C}$. Although some white rust was observed at all temperatures examined, disease severity decreased for temperatures outside of the optimum range. Within the optimum range, severity of white rust ranged from 70 to $90 \%$ when plants were exposed to an 84-h wetness period. As temperatures declined to $6^{\circ} \mathrm{C}$ or increased to $28^{\circ} \mathrm{C}$, disease severity approached $0 \%$. The minimum duration of wetness required for infection and disease development was from 3 to $12 \mathrm{~h}$ depending upon temperature. However, disease severity increased with duration of wetness at temperatures from 8 to $26^{\circ} \mathrm{C}$. A multiple regression model describing the response surface of disease severity to temperature and duration of wetness included significant effects of wetness, temperature, and the interaction between temperature and wetness (19).

Leaf wetness has been used to predict the need for fungicide applications for control of white rust (5). Applications of chlorothalonil and metalaxyl were made after various periods of continuous leaf wetness. Disease incidence where applications were made after a period of $12 \mathrm{~h}$ of continuous leaf wetness did not differ from a calendar-based spray program. Using the advisory program that based fungicide application on $12 \mathrm{~h}$ of continuous leaf wetness, the number of applications was reduced by one or two per season compared with calendar-based programs (5).

Knowledge of the role of environmental factors in disease initiation and development is important for optimizing the efficiency of fungicide programs. Although the use of leaf wetness was effective to this end (5), accounting for the significant effects of temperature may further improve the efficacy of an advisory program for control of white rust. The objectives of this study were to (i) develop and evaluate several weather-based advisory programs for control of white rust that were based on the results of previous studies under controlled conditions (19); and (ii) compare the efficacy of these advisory programs with a protectant versus a systemic fungicide. A brief report of this research has been previously published (17).

\section{MATERIALS AND METHODS}

Field trial design and maintenance. The effects of fungicide programs on control of white rust were evaluated in three field trials at the Plant Pathology Research Farm, Oklahoma State University, Stillwater. The white rust-susceptible spinach cultivar Melody was used in all trials (19). For trial 1, granular fertilizer was broadcast at 45-54-54 kg/ha N-P-K and incorporated prior to direct seeding on 18 September 1998 in a field of Norge loam previously cropped to winter peas. Metolachlor (Dual 8E, Syngenta Crop Protection, Inc., Greensboro, NC) was broadcast at $0.73 \mathrm{~kg} / \mathrm{ha}$ immediately after planting to control weeds. Plots were top-dressed with 45-0-0 kg/ha N-P-K fertilizer 3 weeks after emergence. The spinach from trial 1 was overwintered, mowed, and treatments for trial 2 applied to the new growth. Plots were top-dressed with $45-0-0 \mathrm{~kg} / \mathrm{ha} \mathrm{N}-\mathrm{P}-\mathrm{K}$ fertilizer after mowing on 17 February 1999. For trial 3, fertilizer was broadcast at 84-0-0 kg/ha N-P-K and incorporated prior to direct seeding on 24 February 1999 in a field of Norge loam previously planted to wheat. Metolachlor was broadcast for weed control as previously described, and the spinach was top-dressed with 28-0-0 $\mathrm{kg} / \mathrm{ha} \mathrm{N}-\mathrm{P}-\mathrm{K}$ fertilizer on 1 April. The trials received sprinkler irrigation as necessary to prevent moisture stress.

Treatments consisted of a protectant and a systemic fungicide, each applied according to a calendar-based schedule and various weather-based advisory programs. Treatments were arranged in a randomized complete block design with four blocks. For trials 1 and 2, plots consisted of four 4.6-m-long rows spaced $0.36 \mathrm{~m}$ apart. For trial 3, plots consisted of four 12.2-m-long rows spaced $0.36 \mathrm{~m}$ apart. Alleys (1.5 to $2.1 \mathrm{~m}$ long) between blocks were planted with spinach to serve as spreader rows in each trial. In trial 1 , alleys were inoculated at dusk on 22 October 1998 with a sporangial suspension $\left(1 \times 10^{5}\right.$ sporangia per $\left.\mathrm{ml}\right)$ of $A$. occidentalis. The suspension was prepared by agitating leaf pieces with rust pustules in distilled water and adjusting the concentration according to sporangial counts made with a hemacytometer (19). Inoculation was not necessary in trials 2 and 3 , because plots became infected naturally.

An EBDC fungicide was used for the protectant treatment in each trial. Mancozeb as Dithane 75 DF (Rohm and Haas Co., Philadelphia, PA) was used in trial 1 at $2.24 \mathrm{~kg}$ a.i./ha. Maneb as Manex $4 \mathrm{~F}$ (Griffin L.L.C., Valdosta, GA) and as Maneb 75DF (Elf Atochem North America Inc., Philadelphia, PA) were used at 2.24 $\mathrm{kg}$ a.i./ha in trials 2 and 3 , respectively. The systemic fungicide azoxystrobin as Quadris 2.08F (Syngenta Crop Protection Inc., Greensboro, NC) was used at $0.16 \mathrm{~kg}$ a.i./ha in trials 1 and 2 , and at $0.23 \mathrm{~kg}$ a.i./ha in trial 3. Fungicides were broadcast onto all four rows of a plot using a $\mathrm{CO}_{2}$ pressurized wheelbarrow sprayer equipped with three 8003vk flat-fan nozzles (Spraying Systems Co., Wheaton, IL) spaced 46 $\mathrm{cm}$ apart. The sprayer was calibrated to deliver 314 to 338 liters/ha at $290 \mathrm{kPa}$.

Development of spray thresholds. Weather-based spray thresholds were developed by examining the relationship of disease severity to temperature ( $\mathrm{T}$ ) and duration of wetness (W), as determined previously (19). The weather-based programs accumulated periods of favorable weather for infection of spinach by $A$. occidentalis and development of white rust. Leaf wetness was assumed to occur when the relative humidity (RH) was $\geq 90 \%$. Wetness periods were defined as the duration of $\mathrm{RH}>90 \%$, rather than $\mathrm{RH} \geq$ $95 \%$ (19), to ensure the inclusion of all periods of wetness. Due to the interactive effects of temperature and wetness (19), each hour of wetness was weighted by a factor that accounted for the effect of temperature. At the optimum temperatures of 12 to $18^{\circ} \mathrm{C}$, each hour of wetness was counted as a favorable hour of weather, herein termed a $\mathrm{T}^{*} \mathrm{~W}$ hour. At suboptimal temperatures of 10 to $11^{\circ} \mathrm{C}$ or 19 to $21^{\circ} \mathrm{C}$, each hour of wetness was multiplied by 0.75; and at temperatures from 6 to $9^{\circ} \mathrm{C}$ or from 22 to $26^{\circ} \mathrm{C}$, each hour of wetness was multiplied by 0.50 . At temperatures of $\leq 5^{\circ} \mathrm{C}$ or $\geq 27^{\circ} \mathrm{C}$, each hour of wetness was multiplied by 0 , because little or no disease was observed at these temperatures (19). Spray thresholds of 3, 6, 12, 24, and 36 accumulated $\mathrm{T}^{*} \mathrm{~W}$ hours were tested in each trial.

Spray programs. Weather-based advisory programs were compared with a 7-day calendar program, a nonsprayed control treatment, and a modification of the previously published program based on $12 \mathrm{~h}$ of continuous leaf wetness (5). The original program measured leaf wetness directly with a leaf wetness hygrothermograph. In this study, the spray threshold was defined as $12 \mathrm{~h}$ of continuous $\mathrm{RH}>90 \%$ (12-h W).

Fungicide applications for the 7-day program, and the accumulation of $\mathrm{T} * \mathrm{~W}$ and $\mathrm{W}$ hours for the advisory programs, were initiated when the first true leaves were fully expanded on 23 October 1998, 17 March 1999, and 19 March 1999 for trials 1,2 , and 3 , respectively. The first fungicide application for all $\mathrm{T} * \mathrm{~W}$ programs and the 12-h W program were made when the respective thresholds were first reached. Applications were made as soon as possible after thresholds were reached, usually within 2 days. A 7-day protection interval was observed following an application made according to any of the advisory programs, after which $\mathrm{T}^{*} \mathrm{~W}$ or $\mathrm{W}$ hours were reset to zero and again accumulated. All spray programs were maintained until 7 days before anticipated harvest.

Temperature and wetness were monitored continuously using the Oklahoma MESONET, a network of automated, computer-linked weather stations. Data for the trials were collected from a weather station ca. $0.5 \mathrm{~km}$ from the test site. Temperature and $\mathrm{RH}$ readings were taken every $5 \mathrm{~min}$ to generate a 15 -min mean. The 15 -min mean data were processed using SAS (Version 6.11, SAS Institute, Cary, NC) to provide advisory program outputs for a 24 -h period beginning at $1200 \mathrm{CST}$. The program output included the cumulative number of $\mathrm{T} * \mathrm{~W}$ hours and the number of consecutive hours of wetness.

Disease assessment. Disease incidence, the percentage of leaves with symptoms, and disease severity, the percentage of leaf 
area with symptoms, were evaluated at the end of the cropping season on 16 December 1998, 22 April 1999, and 26 April 1999 for trials 1,2 , and 3, respectively. Six 0.31$\mathrm{m}$ row segments were harvested arbitrarily from the middle two rows of each plot. The harvested leaves were bulked, mixed, and 40 leaves were sampled blindly for further evaluation. Leaves were sorted as asymptomatic or symptomatic to determine disease incidence. The percentage of the abaxial area of each leaf covered with white rust pustules was estimated visually. To assess disease severity, leaves were sorted into five classes from 1 to $50 \%$ using diagrams of white rust severity (4) as a guide. Two additional classes of disease severity, 51 to $75 \%$ and 76 to $100 \%$, were added. The mean percent leaf area with pustules was then calculated using class frequencies and the midpoint value between classes (4).

Data analysis. Analysis of variance was performed on the disease incidence and severity data using the MIXED procedure of SAS (Version 8.2). The effects of fungicide, spray program, and their interaction were tested. Trials were considered experimental replicates, and the effects of trial along with the interaction of trial with other factors (fungicide, spray program, and block) were pooled into error terms along with the effects of block and block interactions with the other factors. Because comparing the efficacy of weather-based advisory programs with a protectant versus systemic fungicide was an objective, subsequent analysis was performed by fungicide. For $\mathrm{T}^{*} \mathrm{~W}$ advisory programs, the application thresholds formed a continuous variable from 3 to $48 \mathrm{~h}$. Therefore, orthogonal contrasts of linear, quadratic, and lack of fit effects (15) were performed within the MIXED Procedure and were considered significant at $P \leq 0.05$. Since the $\mathrm{T} * \mathrm{~W}$ thresholds were not equally spaced, an ORPOL function in the IML procedure of SAS (Version 8.2) was used to obtain the necessary coefficients. Least square means over the three trials for each advisory program were compared with the untreated control at $P \leq 0.05$ using Dunnett's procedure and with the 7-day calendar program using a $t$ test (15). The effects $(P>F)$ of spray program within each fungicide and the effects of fungicide within each spray program were evaluated using the SLICE option of the LSMEANS statement in the MIXED Procedure. The number of fungicide applications made according to each spray program was evaluated as described above except that trials were considered blocks because the number of applications for each spray program was the same for each block and fungicide within trial. Unless otherwise indicated, only significant $(P \leq 0.05)$ differences between treatment means are described below.

\section{RESULTS}

Weather conditions that favored development of white rust, the only foliar disease that was encountered in the three trials, occurred during each trial. Rainfall from emergence to harvest totaled $31.3 \mathrm{~cm}$ in trial $1,16.4 \mathrm{~cm}$ in trial 2 , and $27.1 \mathrm{~cm}$ in trial 3. Each trial received two supplemental irrigations, each at $2.5 \mathrm{~cm}$ water. $\mathrm{T}^{*} \mathrm{~W}$ hours totaled 182 in trial 1,192 in trial 2, and 230 in trial 3 . Wetness periods of $12 \mathrm{~h}$ or longer in duration totaled $50.0 \mathrm{~h}$ in trial $1,12.2 \mathrm{~h}$ in trial $2,25.2 \mathrm{~h}$ in trial 3 .

The number of fungicide applications for the 7-day calendar program averaged 5.7 per trial. Over the three trials, all advisory programs except for the $3-\mathrm{h} \mathrm{T}^{*} \mathrm{~W}$ program resulted in a reduced number of fungicide applications compared with the 7-day program (Table 1). For the $\mathrm{T}^{*} \mathrm{~W}$

Table 1. Number of fungicide applications for control of spinach white rust made according to a calendar-based schedule and weather-based advisory programs over three trials during 1998 and 1999

\begin{tabular}{|c|c|c|c|c|c|}
\hline \multirow[b]{2}{*}{ Spray program $^{v}$} & \multicolumn{3}{|c|}{ Trial } & \multirow[b]{2}{*}{ Mean } & \multirow{2}{*}{$\begin{array}{r}P>T \text { vs. } \\
\text { 7-dayw }\end{array}$} \\
\hline & 1 & 2 & 3 & & \\
\hline 7-day & 8 & 5 & 4 & 5.7 & \\
\hline 3-h T*W & 6 & 3 & 4 & 4.3 & 0.08 \\
\hline $6-\mathrm{h} \mathrm{T} * \mathrm{~W}$ & 5 & 2 & 2 & 3.0 & $<0.01$ \\
\hline $12-\mathrm{h} \mathrm{T} * \mathrm{~W}$ & 4 & 2 & 2 & 2.7 & $<0.01$ \\
\hline 24-h T*W & 3 & 1 & 2 & 2.0 & $<0.01$ \\
\hline $36-\mathrm{h} \mathrm{T} * \mathrm{~W}$ & 3 & 1 & 2 & 2.0 & $<0.01$ \\
\hline $12-\mathrm{h} \mathrm{W}$ & 3 & 1 & 2 & 2.0 & $<0.01$ \\
\hline$P>F$ linear (3-h to $36-\mathrm{h} \mathrm{T} * \mathrm{~W})^{\mathrm{x}}$ & & & & $<0.01$ & \\
\hline$P>F$ quadratic $\left(3-\mathrm{h} \text { to } 36-\mathrm{h} \mathrm{T}^{*} \mathrm{~W}\right)^{\mathrm{y}}$ & & & & 0.03 & \\
\hline$P>F$ lack of fit (3-h to $\left.36-\mathrm{h} \mathrm{T}^{*} \mathrm{~W}\right)^{\mathrm{z}}$ & & & & 0.25 & \\
\hline
\end{tabular}

v 7-day = calendar-based schedule, $\mathrm{N}-\mathrm{h} \mathrm{T} * \mathrm{~W}=$ weather-based advisory programs with application thresholds of $\mathrm{N}$ cumulative hours of wetness (relative humidity $\geq 90 \%$; W) weighted by temperature (T; see text), and $12-\mathrm{h} \mathrm{W}=$ weather-based advisory program with an application threshold of 12 continuous hours of wetness.

${ }^{\text {w }}$ Preplanned comparisons of each spray program mean with the nontreated control using Dunnett's procedure.

${ }^{\mathrm{x}}$ Single degree of freedom contrast for linear effect of $\mathrm{T} * \mathrm{~W}$ threshold ( $3 \mathrm{~h}$ to $36 \mathrm{~h}$ ).

${ }^{y}$ Single degree of freedom contrast for quadratic effect of $\mathrm{T}^{*} \mathrm{~W}$ threshold ( $3 \mathrm{~h}$ to $36 \mathrm{~h}$ ).

${ }^{\mathrm{z}}$ Lack of fit (2 df) for linear and quadratic contrasts. advisory programs, there was a quadratic decline in the number of applications with increasing $\mathrm{T} * \mathrm{~W}$ threshold (Table 1). The number of applications declined with $\mathrm{T}^{*} \mathrm{~W}$ threshold from 4.3 sprays per trial for the 3-h $\mathrm{T} * \mathrm{~W}$ program to a minimum of 2.0 sprays per trial for the $24-\mathrm{h}$ and $36-\mathrm{h} \mathrm{T}^{*} \mathrm{~W}$ programs. The $12-\mathrm{h} \mathrm{W}$ program resulted in the same number of applications as the 24$\mathrm{h}$ and $36-\mathrm{h} \mathrm{T} * \mathrm{~W}$ programs.

Levels of white rust in the nontreated control plots were severe in each trial (Tables 2 and 3). Disease incidence for the nontreated control was $74 \%$ in trial 1 and exceeded $90 \%$ in trials 2 and 3. Disease severity for the nontreated control was $25.5 \%$ in trial 1 and exceeded $50 \%$ in trials 2 and 3 . In the analysis of variance, the main effects of fungicide and spray program were significant $(P<0.01)$. In general, azoxystrobin provided better control of white rust than the EBDC fungicides. Averaged across all spray programs, disease incidence and severity were 56.6 and $9.1 \%$ for the EBDC fungicides compared with 25.3 and $6.5 \%$ for azoxystrobin, respectively. The interaction of fungicide and spray program was not significant for disease incidence $(P=0.55)$. Use of azoxystrobin resulted in reduced disease incidence compared with the EBDC fungicides within each of the spray programs $(P<$ 0.01). The interaction of fungicide and spray program was significant for disease severity $(P<0.01)$. Azoxystrobin application resulted in reduced disease severity compared with the EBDC fungicides for the 3-h T*W $(P=0.03)$, 6-h T*W $(P=$ $0.02), 12-\mathrm{h} \mathrm{T} * \mathrm{~W}(P<0.01), 24-\mathrm{h} \mathrm{T}^{*} \mathrm{~W}(P$ $<0.01), 36-\mathrm{h} \mathrm{T} * \mathrm{~W}(P<0.01)$, and $12-\mathrm{h} \mathrm{W}$ $(P<0.01)$ programs. However, disease severity did not differ between fungicides for the 7-day calendar program $(P=0.07)$. The effect of spray program on disease incidence and severity was significant for both the EBDC fungicides $(P<0.01)$ and azoxystrobin $(P<0.01)$.

When EBDC fungicides were applied, all advisory programs except the $36-\mathrm{h} T * \mathrm{~W}$ and $12-\mathrm{h} \mathrm{W}$ programs resulted in reduced disease incidence compared with the nontreated control (Table 2). The response of disease severity to the advisory programs was similar to disease incidence, except that only the $36-\mathrm{h} \mathrm{T} * \mathrm{~W}$ program did not differ from the nontreated control. The most effective advisory programs for control of white rust were the 3-h $\mathrm{T}^{*} \mathrm{~W}$ and 6$\mathrm{h} \mathrm{T} * \mathrm{~W}$ programs, which did not differ in disease incidence or severity compared with the 7-day calendar program. Use of the other $\mathrm{T}^{*} \mathrm{~W}$ programs and the $12-\mathrm{h} \mathrm{W}$ program resulted in higher levels of disease incidence and severity compared with the 7-day program. For the $\mathrm{T} * \mathrm{~W}$ advisory programs, there was a linear increase in disease incidence with $\mathrm{T} * \mathrm{~W}$ threshold from a low of $39.2 \%$ for the 3-h threshold to a maximum of $85.6 \%$ for the $36-\mathrm{h}$ threshold (Table 2). The response of dis- 
ease severity to $\mathrm{T}^{*} \mathrm{~W}$ threshold was quadratic. Disease severity increased gradually from $5.5 \%$ at the 3 -h threshold to $10.6 \%$ at 12-h threshold, but sharply thereafter to reach a maximum of $45.9 \%$ at the 36-h threshold.

When the fungicide azoxystrobin was used, all advisory programs resulted in reduced disease incidence and severity compared with the nontreated control (Table 3$)$. The most effective advisory programs for control of white rust were the 3$\mathrm{h}, 6-\mathrm{h}$, and $12-\mathrm{h} \mathrm{T}^{*} \mathrm{~W}$ programs, which did not differ in disease incidence and severity from the 7-day calendar program. Levels of disease incidence and severity for the 24-h and 36-h $\mathrm{T}^{*} \mathrm{~W}$ programs and the 12-h $\mathrm{W}$ programs were greater than for the 7day program. For the $\mathrm{T} * \mathrm{~W}$ advisory programs, there was a quadratic increase in disease incidence and severity with threshold duration (Table 3). Disease severity was nearly level at 12.2 to $13.3 \%$ for the 3 $\mathrm{h}$ through $12-\mathrm{h} \mathrm{T}^{*} \mathrm{~W}$ thresholds and increased to a maximum of $54.1 \%$ at the $36-$ $\mathrm{h}$ threshold. Disease severity remained near $1 \%$ from the 3 -h through $12-\mathrm{h} \mathrm{T} * \mathrm{~W}$ thresholds and increased to 8 and $14 \%$ at the $24-\mathrm{h}$ and $36-\mathrm{h} \mathrm{T} * \mathrm{~W}$ thresholds, respectively.

\section{DISCUSSION}

Weather-based advisory programs, based on the development of white rust in response to temperature and duration of wetness under controlled conditions (19), were developed that resulted in improved efficiency of foliar fungicide applications for control of white rust of spinach. The effi-

Table 2. Comparison of a calendar-based schedule and weather-based advisory programs using EBDC fungicides for control of white rust on the susceptible spinach cultivar Melody in three trials during 1998 and 1999r

\begin{tabular}{|c|c|c|c|c|c|c|c|c|c|c|c|c|}
\hline \multirow{3}{*}{$\begin{array}{l}\text { Spray } \\
\text { program }^{u}\end{array}$} & \multicolumn{6}{|c|}{ Disease incidence $(\%)^{\mathrm{s}}$} & \multicolumn{6}{|c|}{ Disease severity $(\%)^{t}$} \\
\hline & \multicolumn{3}{|c|}{ Trial } & \multirow[b]{2}{*}{ Mean } & \multirow{2}{*}{$\begin{array}{l}P>T \text { vs. } \\
\text { control }^{v}\end{array}$} & \multirow{2}{*}{$\begin{array}{c}P>T \text { vs. } \\
\text { 7-day }\end{array}$} & \multicolumn{3}{|c|}{ Trial } & \multirow[b]{2}{*}{ Mean } & \multirow{2}{*}{$\begin{array}{c}P>T \text { vs. } \\
\text { control }\end{array}$} & \multirow{2}{*}{$\begin{array}{c}P>T \text { vs. } \\
\text { 7-day }\end{array}$} \\
\hline & 1 & 2 & 3 & & & & 1 & 2 & 3 & & & \\
\hline 7-day & 29.0 & 39.5 & 47.8 & 38.8 & $<0.01$ & & 3.5 & 2.8 & 10.3 & 5.5 & $<0.01$ & \\
\hline $3-\mathrm{h} \mathrm{T}^{*} \mathrm{~W}$ & 29.0 & 39.0 & 49.5 & 39.2 & $<0.01$ & 0.91 & 3.3 & 2.9 & 12.5 & 6.2 & $<0.01$ & 0.77 \\
\hline $6-\mathrm{h} \mathrm{T}^{*} \mathrm{~W}$ & 31.5 & 42.0 & 50.0 & 41.2 & $<0.01$ & 0.54 & 3.4 & 3.9 & 14.4 & 7.2 & $<0.01$ & 0.50 \\
\hline 12-h T*W & 31.5 & 44.0 & 67.8 & 47.8 & $<0.01$ & 0.02 & 3.6 & 9.7 & 18.4 & 10.6 & $<0.01$ & 0.05 \\
\hline 24-h T*W & 47.0 & 75.3 & 71.3 & 64.5 & $<0.01$ & $<0.01$ & 14.1 & 27.3 & 26.3 & 22.5 & $<0.01$ & $<0.01$ \\
\hline 36-h T*W & 71.5 & 90.0 & 95.3 & 85.6 & 0.99 & $<0.01$ & 24.4 & 56.3 & 56.9 & 45.9 & 0.99 & $<0.01$ \\
\hline 12-h W & 70.8 & 73.3 & 94.0 & 79.3 & 0.13 & $<0.01$ & 24.7 & 28.4 & 53.7 & 35.6 & $<0.01$ & $<0.01$ \\
\hline Control & 73.8 & 94.5 & 98.3 & 88.8 & & $<0.01$ & 25.5 & 57.1 & 60.0 & 47.5 & & $<0.01$ \\
\hline \multicolumn{4}{|c|}{$P>F$ linear $\left(3-\mathrm{h} \text { to } 36-\mathrm{h} \mathrm{T}^{*} \mathrm{~W}\right)^{\mathrm{x}}$} & $<0.01$ & & & & & & & $<0.01$ & \\
\hline \multicolumn{4}{|c|}{$P>F$ quadratic $(3-\mathrm{h} \text { to } 36-\mathrm{h} \mathrm{T} * \mathrm{~W})^{\mathrm{y}}$} & 0.14 & & & & & & & $<0.01$ & \\
\hline \multicolumn{4}{|c|}{$P>F$ lack of fit $\left(3-\mathrm{h} \text { to } 36-\mathrm{h} \mathrm{T}^{*} \mathrm{~W}\right)^{\mathrm{z}}$} & 0.98 & & & & & & & 0.90 & \\
\hline
\end{tabular}

${ }^{\mathrm{r}}$ The EBDC fungicides mancozeb (trial 1) and maneb (trials 2 and 3) were applied at $2.24 \mathrm{~kg}$ a.i./ha.

s Percentage of leaves with white rust from 40 leaves per plot and four replicate blocks for each trial.

${ }^{t}$ Percentage of leaf area with white rust from 40 leaves per plot and four replicate blocks for each trial.

" 7-day $=$ calendar-based schedule, $\mathrm{N}-\mathrm{h} \mathrm{T} * \mathrm{~W}=$ weather-based advisory programs with application thresholds of $\mathrm{N}$ cumulative hours of wetness (relative humidity $\geq 90 \% ; \mathrm{W}$ ) weighted by temperature ( $\mathrm{T}$; see text), and 12-h W = weather-based advisory program with an application threshold of 12 continuous hours of wetness.

v Preplanned comparisons of each spray program mean with the nontreated control using Dunnett's procedure.

${ }^{\text {w }}$ Preplanned comparisons of each spray program mean with the 7-day calendar program using $t$ tests.

${ }^{\mathrm{x}}$ Single degree of freedom contrast for linear effect of $\mathrm{T} * \mathrm{~W}$ threshold $(3 \mathrm{~h}$ to $36 \mathrm{~h})$.

${ }^{\mathrm{y}}$ Single degree of freedom contrast for quadratic effect of T*W threshold ( $3 \mathrm{~h}$ to $36 \mathrm{~h}$ ).

${ }^{\mathrm{z}}$ Lack of fit $(2 \mathrm{df})$ for linear and quadratic contrasts.

Table 3. Comparison of a calendar-based spray schedule and weather-based advisory programs using the fungicide azoxystrobin for control of white rust on the susceptible spinach cultivar Melody in three trials during 1998 and $1999^{\mathrm{r}}$

\begin{tabular}{|c|c|c|c|c|c|c|c|c|c|c|c|c|}
\hline \multirow{3}{*}{$\begin{array}{l}\text { Spray } \\
\text { programu }^{u}\end{array}$} & \multicolumn{6}{|c|}{ Disease incidence $(\%)^{\mathrm{s}}$} & \multicolumn{6}{|c|}{ Disease severity $(\%)^{t}$} \\
\hline & \multicolumn{3}{|c|}{ Trial } & \multirow[b]{2}{*}{ Mean } & \multirow{2}{*}{$\begin{array}{l}P>T \text { vs. } \\
\text { control }^{v}\end{array}$} & \multirow{2}{*}{$\begin{array}{c}P>T \text { vs. } \\
\text { 7-dayw }\end{array}$} & \multicolumn{3}{|c|}{ Trial } & \multirow[b]{2}{*}{ Mean } & \multirow{2}{*}{$\begin{array}{c}P>T \text { vs. } \\
\text { control }\end{array}$} & \multirow{2}{*}{$\underset{\text { 7-day }}{P>T \text { vs. }}$} \\
\hline & 1 & 2 & 3 & & & & 1 & 2 & 3 & & & \\
\hline 7-day & 2.0 & 15.8 & 13.8 & 10.5 & $<0.01$ & & 0.1 & 1.0 & 1.3 & 0.8 & $<0.01$ & \\
\hline 3-h T*W & 2.8 & 20.0 & 13.8 & 12.2 & $<0.01$ & 0.67 & 0.1 & 1.0 & 1.4 & 0.9 & $<0.01$ & 0.99 \\
\hline 6-h T*W & 4.0 & 20.0 & 15.0 & 13.0 & $<0.01$ & 0.52 & 0.4 & 1.1 & 1.7 & 1.1 & $<0.01$ & 0.93 \\
\hline 12-h T*W & 4.0 & 20.0 & 15.8 & 13.3 & $<0.01$ & 0.48 & 0.4 & 1.5 & 1.9 & 1.3 & $<0.01$ & 0.86 \\
\hline 24-h T*W & 8.3 & 45.3 & 34.8 & 29.4 & $<0.01$ & $<0.01$ & 4.7 & 9.0 & 11.4 & 8.4 & $<0.01$ & $<0.01$ \\
\hline 36-h T*W & 12.0 & 79.0 & 71.3 & 54.1 & $<0.01$ & $<0.01$ & 12.2 & 18.5 & 24.0 & 18.3 & $<0.01$ & $<0.01$ \\
\hline $12-\mathrm{h} \mathrm{W}$ & 15.8 & 47.8 & 70.0 & 44.5 & $<0.01$ & $<0.01$ & 12.2 & 9.3 & 24.3 & 15.2 & $<0.01$ & $<0.01$ \\
\hline Control & 73.8 & 94.5 & 98.3 & 88.8 & & $<0.01$ & 25.5 & 57.1 & 60.0 & 47.5 & & $<0.01$ \\
\hline \multirow{3}{*}{\multicolumn{4}{|c|}{$\begin{array}{l}P>F \text { linear }\left(3-\mathrm{h} \text { to } 36-\mathrm{h} \mathrm{T}^{*} \mathrm{~W}\right)^{\mathrm{x}} \\
P>F \text { quadratic }\left(3-\mathrm{h} \text { to } 36-\mathrm{h} \mathrm{T}^{*} \mathrm{~W}\right)^{\mathrm{y}} \\
P>F \text { lack of fit }\left(3-\mathrm{h} \text { to } 36-\mathrm{h} \mathrm{T} \mathrm{T}^{*} \mathrm{~W}\right)^{\mathrm{z}}\end{array}$}} & $<0.01$ & & & & & & $<0.01$ & & \\
\hline & & & & $<0.01$ & & & & & & 0.03 & & \\
\hline & & & & 0.80 & & & & & & 0.87 & & \\
\hline
\end{tabular}

${ }^{\mathrm{r}}$ The fungicide azoxystrobin was applied at $0.17 \mathrm{~kg}$ a.i./ha in trials 1 and 2 , and at $0.22 \mathrm{~kg}$ a.i./ha in trial 3 .

s Percentage of leaves with white rust from 40 leaves per plot and four replicate blocks for each trial.

${ }^{t}$ Percentage of leaf area with white rust from 40 leaves per plot and four replicate blocks for each trial.

u 7-day $=$ calendar-based schedule, $\mathrm{N}-\mathrm{h} \mathrm{T} * \mathrm{~W}=$ weather-based advisory programs with application thresholds of $\mathrm{N}$ cumulative hours of wetness (relative humidity $\geq 90 \%$; W) weighted by temperature ( $\mathrm{T}$; see text), and 12-h W = weather-based advisory program with an application threshold of 12 continuous hours of wetness.

${ }^{\mathrm{v}}$ Preplanned comparisons of each spray program mean with the nontreated control using Dunnett's procedure.

${ }^{\text {w }}$ Preplanned comparisons of each spray program mean with the 7-day calendar program using $t$ tests.

${ }^{\mathrm{x}}$ Single degree of freedom contrast for linear effect of $\mathrm{T} * \mathrm{~W}$ threshold $(3 \mathrm{~h}$ to $36 \mathrm{~h})$.

${ }^{y}$ Single degree of freedom contrast for quadratic effect of $T^{*} \mathrm{~W}$ threshold ( $3 \mathrm{~h}$ to $36 \mathrm{~h}$ ).

${ }^{\mathrm{z}}$ Lack of fit (2 df) for linear and quadratic contrasts. 
ciency of fungicide programs is defined as a maximum level of disease control with a minimum number of fungicide applications. Using the 7-day calendar program as a benchmark, selected $\mathrm{T} * \mathrm{~W}$ advisory programs developed in this study resulted in a reduced number of fungicide applications without sacrificing disease control. However, the number of fungicide applications made and the level of disease control achieved differed among $\mathrm{T} * \mathrm{~W}$ thresholds and between the protectant and systemic fungicides. Based on the statistical comparisons of disease incidence and severity for the $\mathrm{T}^{*} \mathrm{~W}$ programs with the 7-day calendar program, the 6-h and $12-\mathrm{h} \mathrm{T}^{*} \mathrm{~W}$ programs were the most efficient spray programs for the EBDC fungicides and azoxystrobin, respectively.

The accumulation of $\mathrm{T}^{*} \mathrm{~W}$ hours was effective in predicting development of white rust in the field and the need for fungicide application. The 3- to $12-\mathrm{h} \mathrm{T} * \mathrm{~W}$ programs were the most effective advisory programs evaluated in the field. These thresholds are similar to the minimum wetness periods for infection and development of white rust identified under controlled conditions (19). Fewer $\mathrm{T}^{*} \mathrm{~W}$ hours accumulated in trial 1 compared with trials 2 and 3 . The differences in $\mathrm{T}^{*} \mathrm{~W}$ duration among trials corresponded with the higher levels of white rust observed in trials 2 and 3 compared with trial 1. Differences in levels of disease between trials did not appear to be associated with rainfall accumulation or the total duration of wetness periods that exceeded a 12 -h in length.

In contrast to the 3 - to $12-\mathrm{h} \mathrm{T}^{*} \mathrm{~W}$ programs, application of fungicides according to the $12-\mathrm{h} \mathrm{W}$ program resulted in higher level of white rust compared with the 7day calendar program. When EBDC fungicides were used, the $12-\mathrm{h} \mathrm{W}$ program did not reduce disease incidence compared with the nontreated control. Disease control with the EBDC fungicides and azoxystrobin applied according to the 12-h W program were generally similar to the 24and $36-\mathrm{h} T * \mathrm{~W}$ programs, which were less effective than the 7-day calendar program. The improved disease control with the $\mathrm{T}^{*} \mathrm{~W}$ programs may be attributed to the incorporation of the important effects of temperature (19) into the calculation of spray thresholds. However, results of this study differed from those of Dainello and Jones (5), who showed that fungicide applications made following a $12-\mathrm{h} \mathrm{W}$ period were effective in reducing the number of sprays without significantly reducing the level of disease control when compared with calendar-based programs. Differences between these two studies may be a reflection of the method used in measuring wetness duration. Leaf wetness was measured directly with a leaf wetness hygrothermograph by Dainello and Jones (5). In this study, leaf wetness was not measured directly, but continuous hours of $\mathrm{RH}>90 \%$ were used as an approximation of leaf wetness. Twelve continuous hours of RH > $90 \%$ occurred only three times in trial 1 , once in trial 2, and twice in trial 3 . It is possible that the duration of $\mathrm{RH}>90 \%$ underestimates leaf wetness periods. Following periods of high relative humidity and dew formation, leaves may remain wet for some period after RH drops below $90 \%$. In this study, weather variables were recorded using the Oklahoma MESONET network of remote weather stations. This was done in anticipation of using the statewide network in the future implementation of a spray advisory program for white rust.

When applied according to any one of the advisory programs, the systemic fungicide azoxystrobin reduced incidence and severity of white rust compared with the protectant EBDC fungicides. For the 7-day calendar program, azoxystrobin reduced the incidence, but not the severity, of white rust compared with the EBDC fungicides. Because EBDC fungicides are no longer registered for use on spinach, often they are not included in efficacy trials. Efficacy of maneb was similar to azoxystrobin in one trial in Oklahoma under low disease pressure (6). Assuming a similar level of efficacy against white rust for EBDC fungicides and azoxystrobin, the improved performance of azoxystrobin against white rust when applied according to an advisory program might be explained by postinfection activity. Strobilurin fungicides are reported to have postinfection activity against diseases such as apple scab (21). In greenhouse inoculations, applications of maneb $24 \mathrm{~h}$ before or at inoculation prevented white rust development, while azoxystrobin prevented white rust development up to $24 \mathrm{~h}$ after inoculation (18). Similar improvements in disease control with systemic fungicides applied according to weather-based advisory programs have been reported for late blight of potato (14) and early leaf spot of peanut (8). Fungicides that inhibit mycelial growth such as azoxystrobin are likely to perform better that protectants under a weather-based advisory program because sprays are typically recommended during or after periods of weather conducive to infection and disease development.

Strobilurin fungicides such as azoxystrobin inhibit fungal respiration by binding to the mitochondrial $\mathrm{bc}_{1}$ complex, thus blocking electron transfer and ATP synthesis (21). Because of their highly specific mode of action, there is concern over the development and selection of pathogen subpopulations with resistance to strobilurin fungicides. Resistance to strobilurin fungicides has already been reported in gummy stem blight of cucurbits (16), powdery and downy mildews of cucurbits (9), and gray leaf spot of perennial ryegrass (20). Labeled use patterns of strobilurin fungicides are designed to prevent the development and selection of resistant subpopulations. For azoxystrobin on spinach, the label permits a maximum of two consecutive applications before switching to a fungicide with a different mode of action. In this study, the EBDC fungicides and azoxystrobin were used exclusively to experimentally evaluate the effects of spray programs using protectant versus systemic fungicides. Options for integrating protectant fungicides into fungicide programs are limited because the EBDC fungicides maneb and zineb are no longer registered for spinach in the United States. Copper hydroxide and copper sulfate are protectants, but occasional phytotoxicity problems and limited efficacy on spinach has restricted their use by growers. Currently, growers are using fosetyl-Al and a premixture of mefenoxam and copper hydroxide in rotation with azoxystrobin. The efficacy of $\mathrm{T} * \mathrm{~W}$ advisory programs using fungicide sequences approved for resistance management is currently being evaluated.

Azoxystrobin is the primary fungicide in use by growers in Oklahoma for control of white rust. Other fungicides under development for use on spinach, such as zoximide and pyraclostrobin, also are systemic and similar in efficacy to azoxystrobin (unpublished data). Therefore, further validation and implementation efforts will focus on the $12-\mathrm{h} \mathrm{T}^{*} \mathrm{~W}$ program. Over the three trials conducted in this study, use of the $12-\mathrm{h} \mathrm{T} * \mathrm{~W}$ program resulted in a reduction of 2.7 sprays per season compared with the 7-day calendar program. Based on the current cost of azoxystrobin at 0.17 $\mathrm{kg} / \mathrm{ha} \quad(\$ 49.72 / \mathrm{ha})$ and application $(\$ 12.35 / \mathrm{ha})$, a reduction of two applications per season would result in a savings of $\$ 124 / \mathrm{ha}$. In the application for an emergency exemption for use of azoxystrobin to control white rust submitted by Oklahoma to the Environmental Protection Agency in 2000 , the cost of spinach production including azoxystrobin was estimated to be $\$ 1,161 /$ ha. The results of this study indicate that disease forecasting using the 12-h $\mathrm{T} * \mathrm{~W}$ program has the potential to reduce the number of fungicide applications required to control white rust and significantly improve the economics of spinach production in Oklahoma.

\section{ACKNOWLEDGMENTS}

The authors thank Sharon von Broembsen and Nathan Walker for reviewing the manuscript. Approved for publication by the Director, Oklahoma Agricultural Experiment Station. This research was funded in part by the Agricultural Experiment Station project H2159.

\section{LITERATURE CITED}

1. Brandenberger, L. P., Correll, J. C., Morelock, T. E., and McNew, R. W. 1994. Characterization of resistance of spinach to white rust (Albugo occidentalis) and downy mildew (Peronospora farinosa f. sp. spinaciae) Phytopathology 84:431-437.

2. Chambers, A. Y., Hadden, C. H., and Merrill, 
S. 1974. Control of white rust of spinach with fungicides. Tenn. Farm Sci. Prog. Rep. 90:3031.

3. Correll, J. C., Morelock, T. E., Black, M. C., Koike, S. T., Brandenberger, L. P., and Dainello, F. J. 1994. Economically important diseases of spinach. Plant Dis. 78:653-660.

4. Dainello, F. J., Black, M. C., and Kunkel, T. E. 1990. Control of white rust of spinach with partial resistance and multiple soil applications of metalaxyl granules. Plant Dis. 74:913-916.

5. Dainello, F. J., and Jones, R. K. 1984. Continuous hours of leaf wetness as a parameter for scheduling fungicide applications to control white rust. Plant Dis. 68:1069-1072.

6. Damicone, J. P., and Bostian, D. B. 1998. Evaluation of fungicides for control of spinach white rust, 1997. Fungic. Nematicide Tests 53:232.

7. Damicone, J. P., Hammer, T. H., and Bostian, D. B. 2000. Evaluation of spray programs for control of white rust in over-wintered spinach, 1999. Fungic. Nematicide Tests (online) Report 55:257. DOI:10.1094/FN55. American Phytopathological Society, St. Paul, MN.

8. Damicone, J. P., Jackson, K. E., Sholar, J. R., and Gregory, M. S. 1994. Evaluation of a weather-based advisory for management of early leaf spot in Oklahoma. Peanut Sci. 21:115-121.

9. Ishii, H., Fraaije, B. A., Sugiyama, T., Noguchi, K., Nishimura, K., Takeda, T., Amano, T., and Hollomon, D. W. 2001. Occurrence and molecular characterization of strobilurin resistance in cucumber powdery mildew and downy mildew. Phytopathology 91:11661171.

10. Johnston, S. A., and Phillips, J. R. 1997. Evaluation of fungicides for the control of white rust of spinach, Fall 1996. Fungic. Nematicide Tests 52:172.

11. Jones, R. K., and Dainello, F. J. 1983. Efficacy of metalaxyl and metalaxyl tank mixes in controlling Albugo occidentalis and Peronospora effusa on spinach (Spinacia oleracea). Plant Dis. 67:405-407.

12. Raabe, R. D. 1951. The effect of certain environal [sic] factors to initiation and development of the white rust disease of spinach. Ph.D. diss. University of Wisconsin, Madison.

13. Raabe, R. D., and Pound, G. S. 1952. Relation of certain environal [sic] factors to initiation and development of the white rust disease of spinach. Phytopathology 42:448-452.

14. Raposo, R., Wilks, D. S., and Fry, W. E. 1993. Evaluation of potato late blight forecasts modified to include weather forecasts: A simulation analysis. Phytopathology 83:103108.

15. Steel, R. G. D., Torrie, J. H., and Dickey, D. A. 1997. Principles and Procedures of Statistics: A Biometrical Approach, 3rd ed McGraw-Hill, New York.

16. Stevenson, K. L., Langston, D. B., Jr., and Seebold, K. W. 2002. Resistance to azoxystrobin in the gummy stem blight pathogen in Georgia. (Abstr.) Phytopathology 92:S79.

17. Sullivan, M. J., and Damicone, J. P. 2000 Epidemiology and management of white rus of spinach. (Abstr.) Phytopathology 90:S128.

18. Sullivan, M. J., and Damicone, J. P. 2001 Postinfection activity of fungicides against white rust of spinach. (Abstr.) Phytopathology 91:S86.

19. Sullivan, M. J., Damicone, J. P., and Payton, M. E. 2002. The effects of temperature and wetness period on the development of spinach white rust. Plant Dis. 86:753-758.

20. Vincelli, P., and Dixon, E. 2002. Resistance to $\mathrm{Q}_{0} \mathrm{I}$ (strobilurin-like) fungicides in isolates of Pyricularia grisea from perennial ryegrass. Plant Dis. 86:235-240.

21. Ypema, H. L., and Gold, R. E. 1999. Kresoxim-methyl: Modification of a naturally occurring compound to produce a new fungicide. Plant Dis. 83:4-17. 